\title{
Commentary
}

\section{Primary neuronal dysmaturation in preterm brain: Important and likely modifiable}

\author{
Joseph J. Volpe $\mathrm{a}^{\mathrm{a}, \mathrm{b}, *}$ \\ ${ }^{a}$ Department of Neurology, Harvard Medical School, Boston, MA, USA \\ ${ }^{\mathrm{b}}$ Department of Pediatric Newborn Medicine, Harvard Medical School, Boston, MA, USA
}

Received 21 September 2020

Accepted 1 October 2020

Keywords: Preterm brain, neuronal dysmaturation, prevention, treatment

\section{Introduction}

The purpose of this Commentary is to discuss recent evidence that primary impairment of neuronal maturation of gray matter structures in the human preterm infant is common, important and likely modifiable. The major cellular element of gray matter structures in the human brain is the neuron. The principal gray matter structures, especially the cerebral cortex, basal ganglia, and thalamus, are crucial determinants of cognitive and related higher functions, developing subsequent to the newborn period. Impaired cognitive functions, including overall intellect, language, behavior, and socialization, occur in at least $50 \%$ of survivors of very preterm birth [1].

In the last trimester of human gestation, development of the cerebral cortex is especially prominent [2]. The principal anatomic features are development of a complex dendritic arbor, elaboration of axonal ramifications, onset of synaptogenesis and establishment of connectivity between cortical regions

\footnotetext{
*Address for correspondence: Joseph J. Volpe, M.D, Department of Pediatric Newborn Medicine, Brigham and Women's Hospital, 221 Longwood Avenue, Room 343C, Boston, MA 02115 USA. Tel.: +1 617525 4145; E-mail: Joseph.volpe@ childrens.harvard.edu.
}

and deep nuclear structures. A variety of imaging studies in survivors of preterm birth have shown disturbances in maturation of gray matter structures [1], manifested by deficits in volumetric growth, microstructure and functional connectivity. The prevailing concept has been that injury to the vulnerable developing cerebral white matter leads secondarily to neuronal dysmaturation [3]. This secondary neuronal dysmaturation results because the preoligodendrocyte fails to ensheath axons, thereby causing, by anterograde and retrograde mechanisms, impairment of neuronal maturation. Recent experimental studies, however, suggest that impaired neuronal maturation also may be a primary event (see later), not related to white matter injury. Moreover, studies of very preterm human infants have shown impaired cognitive functions in the absence of definite white matter injury (see later). The occurrence of primary neuronal dysmaturation has important implications for elucidating the anatomic substrate for the cognitive deficits observed in survivors of preterm birth, and, critically for interventions to restore normal maturation and improve outcome. The following will review the principal experimental and human studies supportive of primary neuronal dysmaturation in the very preterm infant and of potential restorative interventions. 


\section{Experimental studies}

Utilizing an excellent, established animal model of the very preterm infant, i.e., fetal sheep at 0.65 gestation, Back and coworkers demonstrated a marked disturbance in hippocampal neuronal maturation after only a brief (30 minutes) episode of fetal hypoxemia (without ischemia) [4]. Elegant neurobiological techniques showed no neuronal death but, rather, alterations in both basal and apical dendritic arborization over the next several weeks. The anatomical disturbance was accompanied by neurophysiological disturbances characteristic of impaired connectivity and subsequent cognitive disturbances, especially involving working memory. Such functional deficits and impaired hippocampal growth are observed in human preterm survivors [5-7]. Indeed, chronic disturbances of episodic and working memory have been shown to persist into adulthood in very preterm survivors $[8,9]$.

In a similar experimental paradigm, McClendon et al. showed that transient hypoxemia, without ischemia, chronically disrupted maturation of subplate neuronal arborization and physiological activity [10]. Importantly, subplate neuronal death did not occur. This impaired maturation of subplate neurons would have major consequences for development of cerebral cortex and thalamus, as described elsewhere [3]. In human brain from 24-32 weeks, the subplate neuronal layer reaches its maximal size. The dendritic arbor of subplate neurons receives ascending afferents from thalamus and other cortical regions and extends axon collaterals to the overlying cerebral cortex to promote cortical neuronal differentiation, synaptogenesis and cerebral connectivity (thalamocortical, commissural-cortical, cortico-cortical) [3].

The clinical relevance of these experimental studies is substantial. During human pregnancy transient or chronic intrauterine hypoxemia may occur secondary to maternal, placental or fetal causes. In the neonatal period very preterm infants experience transient periods of hypoxemia from respiratory disease, apneic episodes, sepsis or cardiac disease. Indeed, recent studies have delineated cortical neuronal dysmaturation with congenital heart disease in which hypoxemia is prominent [11]. Perhaps of most relevance in this context, exposure to hypoxemia in very preterm infants is associated with subsequent neurodevelopmental disability [12]; such infants may experience up to 600 transient hypoxic episodes per week [13]. Thus, unlike the pathogenesis of overt preterm brain injury, e.g., hypoxic-ischemic white matter injury, the experimental data indicate that primary neuronal dysmaturation can occur as a consequence of hypoxemia alone.

Other apparent examples of primary neuronal dysmaturation are described in related experimental studies of preterm sheep [14, 15]. Neurons of cerebral cortex and caudate nucleus sustain persistent neuronal dysmaturation under conditions of hypoxiaischemia. However, in this paradigm it cannot be ruled out that the neuronal dysmaturation is related secondarily to concomitant white matter injury.

In summary, the experimental studies show that dysmaturation involving hippocampal and subplate neurons occurs following transient hypoxemia. The involvement of hippocampal cortex is consistent with demonstrations of impaired hippocampal growth in human preterm survivors [5-7]. The involvement of subplate neurons is consistent with demonstrations of impaired cerebral and thalamic growth, shown by advanced MRI techniques in similar infants [1].

\section{Human studies}

Primary neuronal dysmaturation, i.e., not secondary to preceding cerebral white matter injury, is indicated by several studies. The most compelling human study involved 95 premature infants studied by advanced MRI methods at two time points in the neonatal period (32 and 40 weeks post-conception) [16]. The serial design was critical to assess maturation. The central finding was evidence for delayed microstructural development of cerebral cortical gray matter at multiple cortical sites. The diffusion-based measurements showed delayed microstructural development in cerebral cortex, but not cerebral white matter, in association with impaired somatic growth. The principal finding was a blunting of the normal developmental decline in fractional anisotropy (FA) in cortex, whereas in cerebral white matter the normal increase in FA was not affected. The developmental decline in FA in cortex is related to the exuberant dendritic development in human premature brain [2], the same aspect of neuronal development shown to be impaired in the experimental studies of McClendon et al. [15] (see earlier). The preservation of the expected increase in FA in cerebral white matter, related to pre-oligodendroglial development and ensheathment of axons [17, 18], is consistent with the absence of concomitant cerebral white matter injury. 
The association of impaired cortical dendritic development with impaired somatic growth in the study of Vinall et al. [16] raises the possibility that undernutrition is particularly involved, but detailed data regarding nutrition, caloric intake, and feeding were not available. However, several studies of premature newborns with intrauterine growth retardation also showed a particular involvement of cerebral cortical development, including reduced cortical volume, reduced cortical surface area, and impaired gyral development [19-22]. Although these latter data concerning intrauterine growth retardation suggest a relation between impaired nutrition in the third trimester of human gestation and primary dysmaturation of cerebral cortical neurons, concomitant white matter involvement cannot be ruled out.

Pain and stress may represent another mediator of primary neuronal dysmaturation in the preterm infant. Pain and stress in the neonatal period, common experiences for the preterm infant, have been shown to have adverse effects on neurodevelopmental, behavioral and cognitive outcome [23-27]. Abnormalities of brain development have involved such neuronalrich areas as cerebral cortex, hippocampus and thalamus, as well as functional connectivity among these structures [26-31]. The studies have quantitated pain and stress (either number of stressful events or number of painful procedures). Although most abnormalities were detected at term equivalent age, cerebral cortical thinning, especially in frontal and parietal areas, was identified at a mean age of 7.9 years [30].

A large body of experimental literature suggests that neuronal maturation and impairment thereof can be influenced by such experiential factors as auditory and visual input [32]. Concerning auditory input, a modulatory effect of the neonatal auditory environment on cortical neuronal development and language outcome is suggested by recent clinical studies [33, 34]. Because of concern about excessive sound levels of neonatal units, ventilators, etc., many units have been designed to minimize such noise, often by maintaining infants in single rooms. That this approach may have an adverse effect on language and cerebral cortical neuronal development is suggested by a study of 136 preterm infants assigned to either openward or single-room bed spaces. Interestingly, the infants cared for in single-patient rooms had lower language scores at age two years and, importantly, abnormalities of cerebral cortical folding in the superior temporal area [33]. The difference in outcomes was attributed to differences in exposure to language in the open areas versus single rooms. In a subsequent study, outcomes were assessed for infants from both single-patient rooms and open-ward bed spaces while quantitating maternal involvement [34]. Infants with high maternal involvement from both single-patient and open-ward bed spaces had higher cognitive and language scores at age 18 months than did infants with lower maternal involvement. The effect size was greater for infants in single rooms. The latter study suggests that the level of language exposure, the likely crucial effector, depends on a variety of factors, including room type and maternal characteristics that allow maternal verbal contact with the infant. That these findings reflect experience disturbing or enhancing neuronal maturation is supported by the concurrence during the last 10-12 weeks of gestation of critical events relating to neuronal development involved in the establishment of auditory connections between brainstem and temporal lobe/auditory cortex $[35,36]$.

Neonatal visual experience also may play a role in neuronal maturation. Development of the visual cortex is very active during the premature period and into infancy [2]. Central visual impairment is a common neurological sequela in very preterm infants and may reflect, in part, neuronal dysmaturation in visual cortex. (White matter injury likely also plays a role in this impairment.). Primary neuronal dysmaturation in visual cortex of human infants has not been studied directly, but considerable data indicate that visual cortical neuronal maturation is active and thereby likely vulnerable [2]. Such maturation could be influenced by the visual experience of premature infants. Thus, the latter experience is associated with accentuation of the development of the visual evoked potential, a finding consistent with experimental studies $[37,38]$. Experimental studies of normal and preterm monkeys showed that premature visual stimulation resulted in increases in size and proportions of synapses in visual cortex, presumably by activity-dependent alterations in synaptogenesis, synaptic modification or synapse elimination [39]. Visual deprivation has opposite and unfavorable effects, consistent with primary neuronal dysmaturation. More data are needed to address how visual experience could enhance development of the cerebral visual system in the human infant and perhaps counteract the effects of dysmaturation.

Many of the specific factors described in the preceding paragraphs, e.g., nutrition, stress, experience, occur in various combinations, often grouped under 
such rubrics as parenting, educational and socioeconomic factors, and appear to influence neuronal maturation. Indeed, primary neuronal dysmaturation appears to be the likely anatomic substrate of the impaired cognition, language and behavior associated with disturbances of such factors in survivors of prematurity. Many studies in recent years support this contention [40-47]. Initial research with MRI has identified impaired volumetric growth of such neuronal-rich areas as cerebral cortex, hippocampus, and thalamus and maturation of functional connectivity among these regions [46-49]. The particular importance of early parenting behavior, particularly maternal affective involvement, parent-child synchrony and positive and responsive parenting, has been delineated and raises the possibility that such characteristics could counteract neuronal dysmaturation.

The relation of the combination of factors associated with socio-economic status to neuronal dysmaturation has been delineated in normal termborn children [50]. Brain imaging has identified disturbances in development of cerebral cortex, thalamus and hippocampus with lower socio-economic status scores. These disturbances might be expected because, post-term, neuronal maturation (elaboration of axonal and dendritic processes, synaptogenesis) is a very active process in the months and early years of infancy. Areas involved in language, learning and memory have been especially affected. Particular involvement of "stress-sensitive" brain regions, e.g., amygdala and hippocampus, also has been identified [50]. Notably, experimental studies suggest that environmental enrichment can counteract the structural and functional disturbances [50]. Initial data from human studies support the notion that such factors as sensitive parenting, reduction of stress, improved nutrition and early childhood intervention, similarly improve outcome, perhaps by enhancing neuronal maturation [50].

\section{Conclusions}

The experimental and human studies described in this Commentary support the notion that primary dysmaturation of neurons in key areas of the preterm and early infant brain is common and a mediator of subsequent cognitive, language, behavioral, socialization deficits observed beyond infancy. Recognition of this dysmaturation is important because specific interventions could prevent, amelio- rate or counteract the deficits. Recent experimental work suggests that recognition and management of hypoxemia in the neonatal intensive care unit setting are important. Also, however, multiple human studies show that factors related to nutrition, pain and stress, auditory and visual experience, parenting, education and socio-economic factors are important in pathogenesis. Moreover, these factors are amenable to modification to ensure optimal neuronal maturation in the neonatal period and beyond.

\section{References}

[1] Neil JJ, Volpe JJ. Encephalopathy of prematurity: Clinicalneurological features, diagnosis, imaging, prognosis, therapy. In: Volpe JJ, Inder TE, du Plessis AJ, Darras BT, Perlman J, Neil J, et al., editors. Volpe's Neurology of the Newborn. Chapter 16, 6th ed. Philadelphia, PA: Elsevier; 2018. pp. 425-57.

[2] Kinney HC, Volpe JJ. Organizational events In: Volpe JJ, Inder TE, Darras BT, deVries LS, duPlessis AJ, Neil JJ, et al., editors. Volpe's Neurology of the Newborn. Chapter 7, 6th ed. Philadelphia, PA: Elsevier; 2018. pp. 145-75.

[3] Volpe JJ. Dysmaturation of premature brain: Importance, cellular mechanisms and potential interventions. Pediatr Neurol. 2019;95:42-66.

[4] McClendon E, Wang K, Degener-O'Brien K, Hagen MW, Gong X, Nguyen T, et al. Transient hypoxemia disrupts anatomical and functional maturation of preterm fetal ovine CA1 pyramidal neurons. J Neurosci. 2019;39:7853-71.

[5] Peterson BS, Vohr B, Staib LH, Cannistraci CJ, Dolberg A, Schneider KC, et al. Regional brain volume abnormalities and long-term cognitive outcome in preterm infants. JAMA. 2000;284:1939-47.

[6] Beauchamp MH, Thompson DK, Howard K, Doyle LW, Egan GF, Inder TE, et al. Preterm infant hippocampal volumes correlate with later working memory deficits. Brain. 2008;131:2986-94.

[7] Thompson DK, Wood SJ, Doyle LW, Warfield SK, Lodygensky GA, Anderson PJ, et al. Neonate hippocampal volumes: prematurity, perinatal predictors, and 2-year outcome. Ann Neurol. 2008;63:642-51.

[8] Nosarti C, Reichenberg A, Murray RM, Cnattingius S, Lambe MP, Yin L, et al. Preterm birth and psychiatric disorders in young adult life. Arch Gen Psychiatr. 2012;69:E1-8.

[9] Nosarti C, Froudist-Walsh S. Alterations in development of hippocampal and cortical memory mechanisms following very preterm birth. Dev Med Child Neurol. 2016;58(Suppl 4):35-45.

[10] McClendon E, Shaver DC, Degener-O'Brien K, Gong $\mathrm{X}$, Nguyen T, Hoerder-Suabedissen A, et al. Transient hypoxemia chronically disrupts maturation of preterm fetal ovine subplate neuron arborization and activity. J Neurosci. 2017;37:11912-29.

[11] Leonetti C, Back SA, Gallo V, Ishibashi N. Cortical dysmaturation in congenital heart disease. Trends Neurosci. 2019;42:192-204.

[12] Poets CF, Roberts RS, Schmidt B, Whyte RK, Asztalos EV, Bader D, et al. Association between intermittent 
hypoxemia or bradycardia and late death or disability in extremely preterm infants. JAMA. 2015;314:595-603.

[13] Di Fiore JM, Bloom JN, Orge F, Schutt A, Schluchter M, Cheruvu VK, et al. A higher incidence of intermittent hypoxemic episodes is associated with severe retinopathy of prematurity. J Pediatr. 2010;157:69-73.

[14] Dean JM, McClendon E, Hansen K, Azimi-Zonooz A, Chen K, Riddle A, et al. Prenatal cerebral ischemia disrupts MRI-defined cortical microstructure through disturbances in neuronal arborization. Sci Transl Med. 2013;5: $168 \mathrm{ra} 7$.

[15] McClendon E, Chen K, Gong X, Sharifnia E, Hagen M, Cai V, et al. Prenatal cerebral ischemia triggers dysmaturation of caudate projection neurons. Ann Neurol. 2014;75: 508-24.

[16] Vinall J, Grunau RE, Brant R, Chau V, Poskitt KJ, Synnes $\mathrm{AR}$, et al. Slower postnatal growth is associated with delayed cerebral cortical maturation in preterm newborns. Sci Transl Med. 2013;5:168ra8.

[17] Huppi PS, Maier SE, Peled S, Zientara GP, Barnes PD, Jolesz FA, et al. Microstructural development of human newborn cerebral white matter assessed in vivo by diffusion tensor magnetic resonance imaging. Pediatr Res. 1998;44:584-90.

[18] Kinney HC, Volpe JJ. Myelination events. In: Volpe JJ, Inder TE, Darras BT, deVries LS, duPlessis AJ, Neil JJ, et al., editors. Volpe's Neurology of the Newborn. Chapter 8, 6th ed. Philadelphia, PA: Elsevier; 2018. pp. 176-88.

[19] Tolsa CB, Zimine S, Warfield SK, Freschi M, Sancho Rossignol A, Lazeyras F, et al. Early alteration of structural and functional brain development in premature infants born with intrauterine growth restriction. Pediatr Res. 2004;56:132-8.

[20] Dubois J, Benders M, Borradori-Tolsa C, Cachia A, Lazeyras F, Ha-Vinh Leuchter R, et al. Primary cortical folding in the human newborn: An early marker of later functional development. Brain. 2008;131:2028-41.

[21] Lodygensky GA, Seghier ML, Warfield SK, Tolsa CB, Sizonenko S, Lazeyras F, et al. Intrauterine growth restriction affects the preterm infant's hippocampus. Pediatr Res. 2008;63:438-43.

[22] Padilla N, Falcon C, Sanz-Cortes M, Figueras F, Bargallo $\mathrm{N}$, Crispi F, et al. Differential effects of intrauterine growth restriction on brain structure and development in preterm infants: A magnetic resonance imaging study. Brain Res. 2011;1382:98-108.

[23] Whitfield MF, Grunau RE. Behavior, pain perception, and the extremely low-birth weight survivor. Clin Perinatol. 2000;27:363-79.

[24] Grunau R. Early pain in preterm infants. A model of longterm effects. Clin Perinatol. 2002;29:373-94, vii-viii.

[25] Doesburg SM, Chau CM, Cheung TP, Moiseev A, Ribary U, Herdman AT, et al. Neonatal pain-related stress, functional cortical activity and visual-perceptual abilities in schoolage children born at extremely low gestational age. Pain. 2013;154:1946-52.

[26] Schneider J, Duerden EG, Guo T, Ng K, Hagmann P, Bickle Graz M, et al. Procedural pain and oral glucose in preterm neonates: brain development and sex-specific effects. Pain. 2018;159:515-25.

[27] Duerden EG, Grunau RE, Guo T, Foong J, Pearson A, AuYoung $\mathrm{S}$, et al. Early procedural pain is associated with regionally-specific alterations in thalamic development in preterm neonates. J Neurosci. 2018;38:878-86.
[28] Smith GC, Gutovich J, Smyser C, Pineda R, Newnham $\mathrm{C}$, Tjoeng $\mathrm{TH}$, et al. Neonatal intensive care unit stress is associated with brain development in preterm infants. Ann Neurol. 2011;70:541-9.

[29] Brummelte S, Grunau RE, Chau V, Poskitt KJ, Brant R, Vinall J, et al. Procedural pain and brain development in premature newborns. Ann Neurol. 2012;71:385-96.

[30] Ranger M, Chau CM, Garg A, Woodward TS, Beg MF, Bjornson B, et al. Neonatal pain-related stress predicts cortical thickness at age 7 years in children born very preterm. PLoS One. 2013;8:e76702.

[31] Duerden EG, Guo T, Dodbiba L, Chakravarty MM, Chau V, Po9skiitt KJ, et al. Midazolam dose correlates with abnormal hippocampal growth and neurodevelopmental outcome in preterm infants. Ann Neurol. 2016;79:548-59.

[32] Kinney HC, Volpe JJ. Encephalopathy of prematurity: Neuropathology. In: Volpe JJ, Inder TE, Darras BT, deVries LS, duPlessis AJ, Neil JJ, et al., editors. Volpe's Neurology of the Newborn. Chapter 14, 6th ed. Philadelphia, PA: Elsevier; 2018. pp. 389-404.

[33] Pineda RG, Neil J, Dierker D, Smyser CD, Wallendorf M, Kidokoro $\mathrm{H}$, et al. Alterations in brain structure and neurodevelopmental outcome in preterm infants hospitalized in different neonatal intensive care unit environments. J Pediatr. 2014;164:52-60.

[34] Lester BM, Salisbury AL, Hawes K, Dansereau LM, Bigsby $\mathrm{R}$, Laptook A, et al. 18-month follow-up of infants cared for in a single-family room neonatal intensive care unit. J Pediatr. 2016;177:84-9.

[35] Starr A, Amlie RN, Martin WH, Sanders S. Development of auditory function in newborn infants revealed by auditory brainstem potentials. Pediatrics. 1977;60:831-9.

[36] Kwon SH, Scheinost D, Vohr B, Lacadie C, Schneider K, Dai $F$, et al. Functional magnetic resonance connectivity studies in infants born preterm: Suggestions of proximate and long-lasting changes in language organization. Dev Med Child Neurol. 2016;58( Suppl 4):28-34.

[37] Tsuneishi S, Casaer P. Effects of preterm extrauterine visual experience on the development of the human visual system: a flash VEP study. Dev Med Child Neurol. 2000;42: 663-8.

[38] Schwindt E, Giordano V, Rona Z, Czaba-Hnizdo C, Olischar $\mathrm{M}$, Waldhoer $\mathrm{T}$, et al. The impact of extrauterine life on visual maturation in extremely preterm born infants. Pediatr Res. 2018;84.

[39] Bourgeois JP, Jastreboff PJ, Rakic P. Synaptogenesis in visual cortex of normal and preterm monkeys: Evidence for intrinsic regulation of synaptic overproduction. PNAS (USA). 1989;86:4297-301.

[40] Brown HK, Speechley KN, Macnab J, Natale R, Campbell MK. Mild prematurity, proximal social processes, and development. Pediatrics. 2014;134:e814-24.

[41] Hair NL, Hanson JL, Wolfe BL, Pollak SD. Association of child poverty, brain development, and academic achievement. JAMA Pediatr. 2015;169:822-9.

[42] Doyle LW, Cheong JL, Burnett A, Roberts G, Lee KJ, Anderson PJ. Biological and social influences on outcomes of extreme-preterm/low-birth weight adolescents. Pediatrics. 2015;136:e1513-e20.

[43] Linsell L, Malouf R, Morris J, Kurinczuk JJ, Marlow N. Prognostic factors for poor cognitive development in children born very preterm or with very low birth weight: A systematic review. JAMA Pediatr. 2015;169: 1162-72. 
[44] Parker MG, Rybin DV, Heeren TC, Thoyre SM, Corwin MJ. Postdischarge feeding interactions and neurodevelopmental outcome at 1-year corrected gestational age. J Pediatr. 2016;174:104-10.

[45] Treyvaud K, Doyle LW, Lee KJ, Ure A, Inder TE, Hunt RW, et al. Parenting behavior at 2 years predicts school-age performance at 7 years in very preterm children. J Child Psychol. Psychiatr 2016;57:814-21.

[46] Lean RE, Paul RA, Smyser TA, Smyser CD, Rogers CE. Social adversity and cognitive, language, and motor development of very preterm children from 2 to 5 years of age. $\mathrm{J}$ Pediatr. 2018;203:177-84 e1.

[47] Leijser LM, Siddiqi A, Miller SP. Imaging evidence of the effect of socio-economic status on brain structure and development. Semin Pediatr Neurol. 2018;27:26-34.
[48] Gao W, Alcauter S, Elton A, Hernandez-Castillo CR, Smith JK, Ramirez J, et al. Functional network development during the first year: Relative sequence and socioeconomic correlations. Cereb Cortex. 2015;25:2919-28.

[49] Betancourt LM, Avants B, Farah MJ, Brodsky NL, Wu J, Ashtari M, et al. Effect of socioeconomic status (SES) disparity on neural development in female African-American infants at age 1 month. Dev Sci. 2016;19:947-56.

[50] Benavente-Fernandez I, Siddiqi A, Miller SP. Socioeconomic status and brain injury in children born preterm: modifying neurodevelopmental outcome. Pediatr Res. 2020;87:391-8 